\title{
The Role of Movement in Data Visualization: Animation as an Agent of Meaning
}

\author{
Valeria Burgio ${ }^{1}$ and Matteo Moretti ${ }^{1}$ \\ ${ }^{1}$ Free University of Bolzano \\ valeria.burgio@unibz.it; matmoretti@unibz.it
}

\begin{abstract}
If we look at data visualizations as signifying machines, in which every element is meaningful, what is the contribution of animation to the construction of meaning? What does motion or animation add in terms of significance to different kinds of graphics? Does it add something in terms of realism? How can animation be an implementer of meaning, dramatizing the sense of data or expressing doubt about the data itself?
\end{abstract}

\section{Introduction}

Animation in graphics can have different functions:

1. At a pre-perceptive level, it draws attention

2. At a syntactic level, it creates connections

3. At a semantic level:

- it introduces time and change into the visualization

- it literally depicts movement

- it highlights and dramatizes certain data.

We will now quickly see some examples of these functions at work, and then focus on two case studies, to see how in these cases animation has been used not only to attract attention, create connections and enhance meaning, but also to introduce new semantic shades in the reading of the data visualization.

\section{Drawing attention}

At a primitive pre-attentive level, one of the first kinds of visual information we get, together with color and texture, is movement (Healey, 2012). This is due to evolutionary strategies for the survival of a man as an animal: as a prey or as a predator, it was vital for a man to detect movement to run away from something trying to catch him, or to catch something running away from him (see Arnheim, 1954, chapter 8; Cairo, 2012: 102-105). Thus, elements moving in a targeted way in a graphic immediately focus and direct the viewer's gaze (also see Finke and Manger, 2012: 184) 


\section{Creating connections}

Movement creates a conjunction between different actions performed by the same subject. It can connect two charts, with a relation of coordination or subordination. Technically speaking, the graphic configuration in fig.1a is a clustered bubble chart, organized as a pie chart. The fact that the passage between the total (fig. 1a) and the single departments (fig. 1b) is animated creates a correlation between the total (in

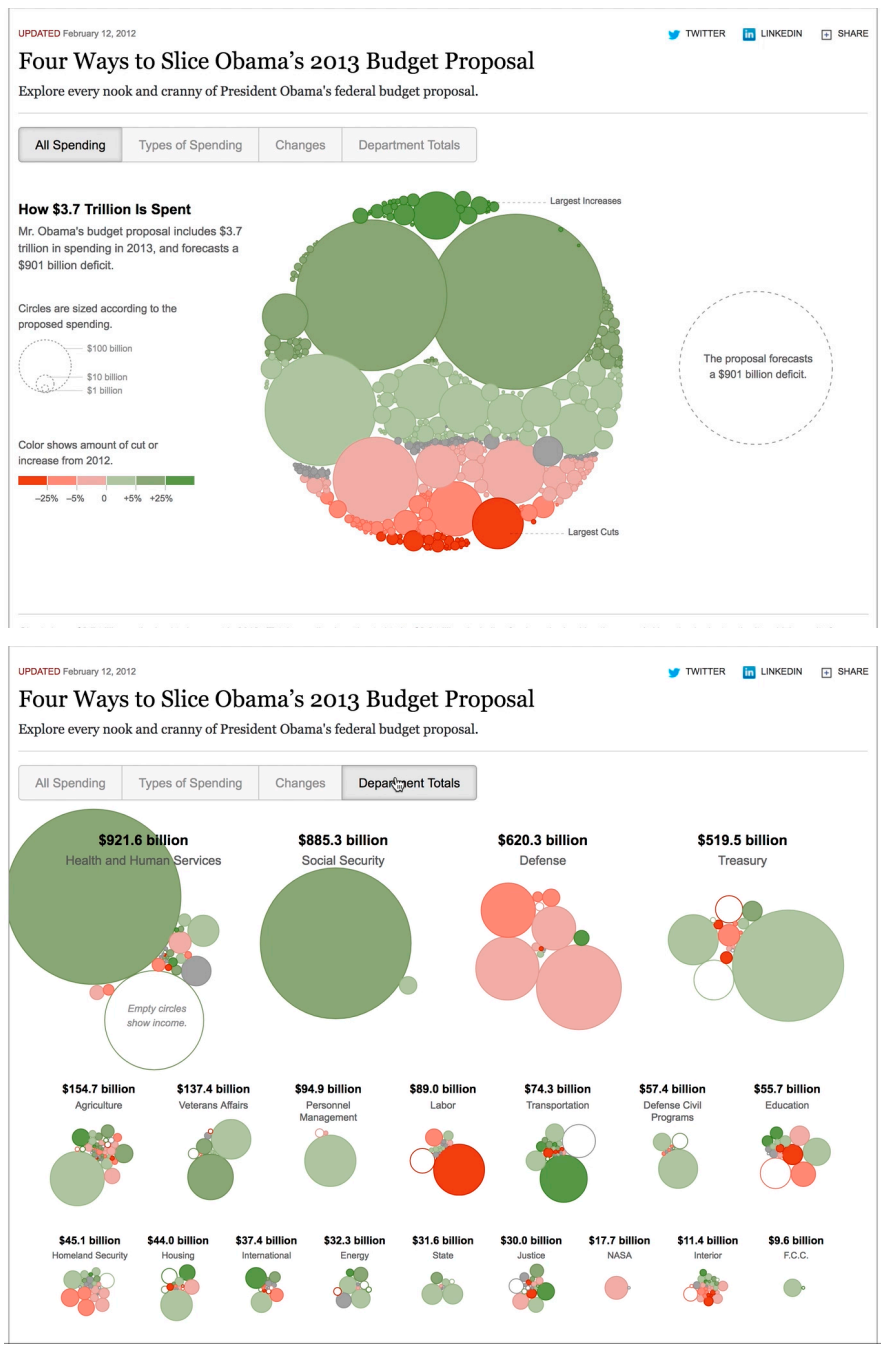

Fig. 1a and 1b. Two frames of the graphic "Four Ways to Slice Obama's 2013 Budget Proposal" published in New York Times, February 12, 2012 (designer: Shan Carter).

https://archive.nytimes.com/www.nytimes.com/interactive/2012/02/13/us/politics/2013budget-proposal-graphic.html 
percentage) and the parts of it, avoiding the accusation to bubble charts to make comparisons and proportions impossible (for a critic of bubble charts, see Tufte, 1983: 71 and Cairo 2012, 39-44). Bubble charts can indeed always be clustered. Here animation allows to focus on one single item without losing connection with the whole subject. It constructs a relation of subordination between the total and the parts, that can be individually analyzed.

\section{Semantic level}

\subsection{Expressing transformation during time}

One of the main functions of motion in graphics is that "temporal sequences of events can be rendered graphically. In addition, time can be slowed or accelerated at will to emphasize or speed up processes" (Finke and Manger, 2012: 24). It is banal to say, but the main contribution of animation in graphics is the introduction of time and progress in the description of a phenomenon, thus also enabling hypotheses for the future. In the famous animated timeline 200 countries, 200 years, 4 minutes directed by Hans Rosling and BBC four (2010), the progressive growth of income and life expectancy in all the world in the last decades let the viewer expect a continuation of the same trend in the future, when everybody is supposed to move towards the top right corner of the screen (fig. 2).

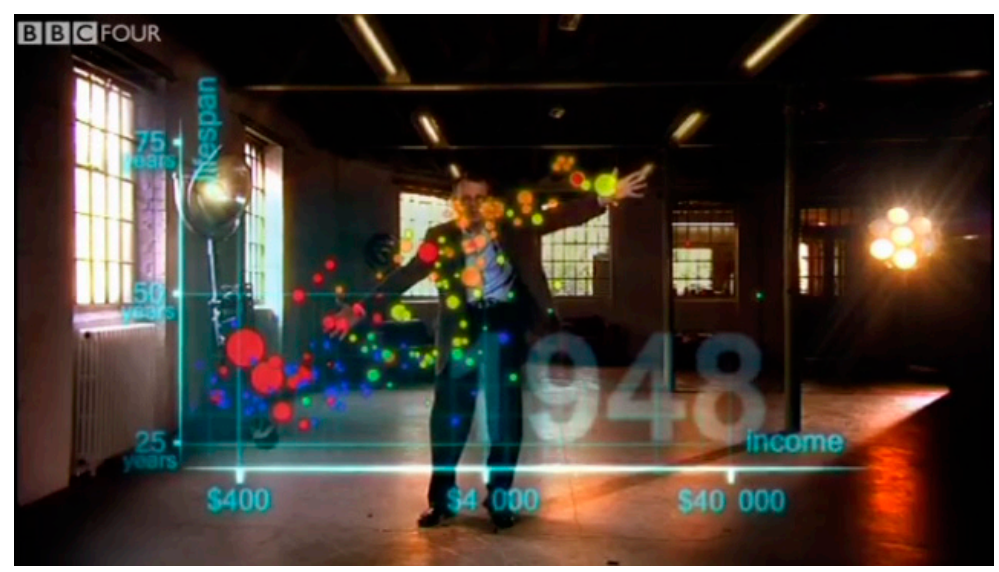

Fig. 2. A frame from the short documentary " 200 countries, 200 years, 4 minutes", Hans Rosling, BBC four, November 30, 2010. http://www.bbc.co.uk/programmes/p00cgkfk

Other animated visualization can on the contrary warn about the possibility of a catastrophic future if trends continue in the same direction they are going now. Diller, Scofidio + Renfro's animated video installation Exit (fig.3), presented at the Fondation Cartier in 2008 and during Copenhagen Summit on climate change in 2009 
let us foresee the increase in mass migration in the 21st century, due to phenomena such as climate change, floods and submersion of coastal land as well as conflicts (Virilio, 2009).

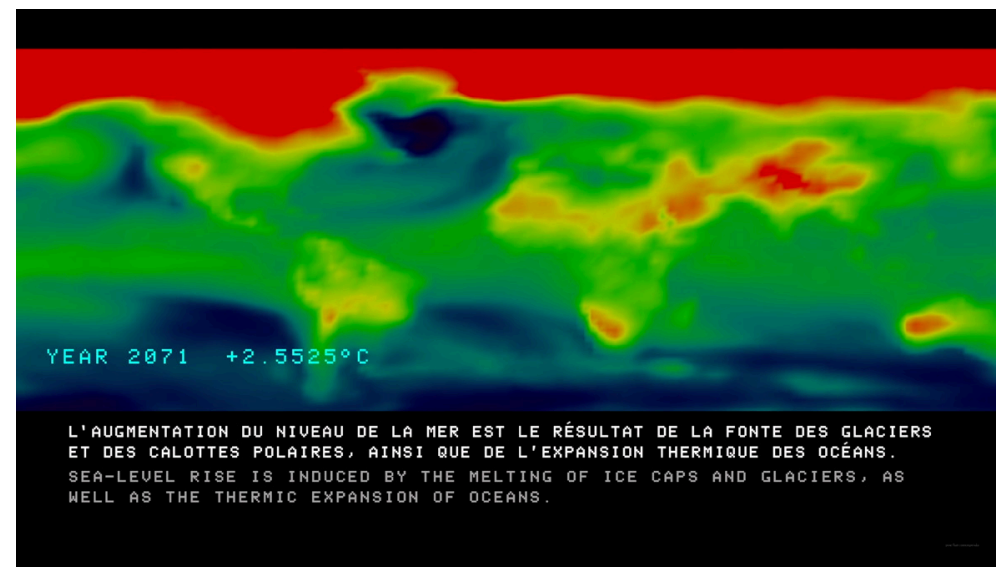

Fig. 3. A frame from the video installation "Exit", 2008-2015. Scenario "Rising Seas, Sinking Cities". Collection Foundation Cartier pour l'Art Contemporain, Paris. CDiller Scofidio + Renfro, Mark Hansen, Laura Kurgan and Ben Rubin.

\subsection{Depicting movement (time + space)}

It is difficult to represent flows in static graphics. Flow is the essence of the moving image. And population flows are the essence of our contemporary times. So, the representation of flows through the traceability of the routes and animated maps go hand in hand (fig. 4 and fig. 5).

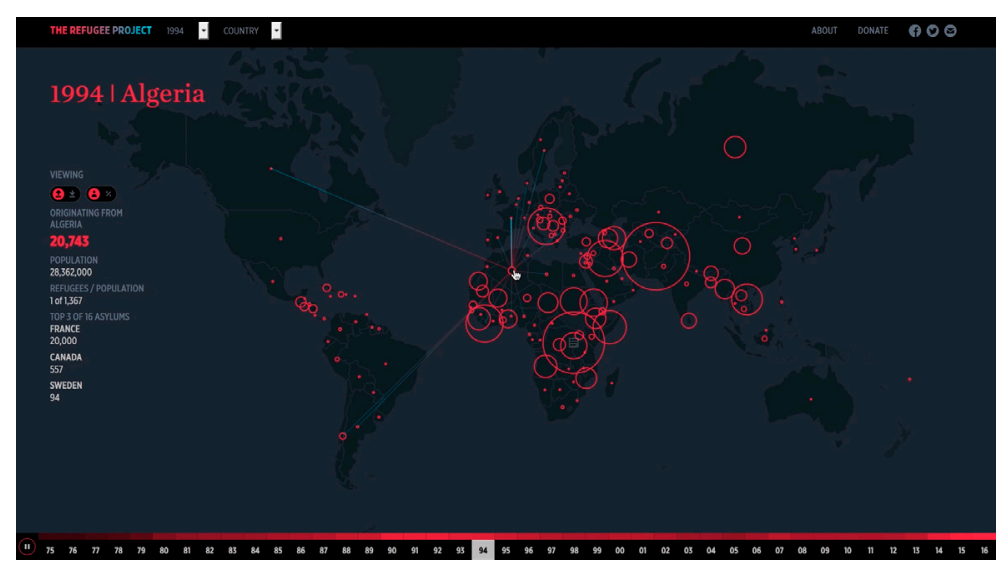

Fig. 4. A frame from The Refugee Project, 2014, by Hyperakt and Ekene Ijeoma. http://www.therefugeeproject.org 


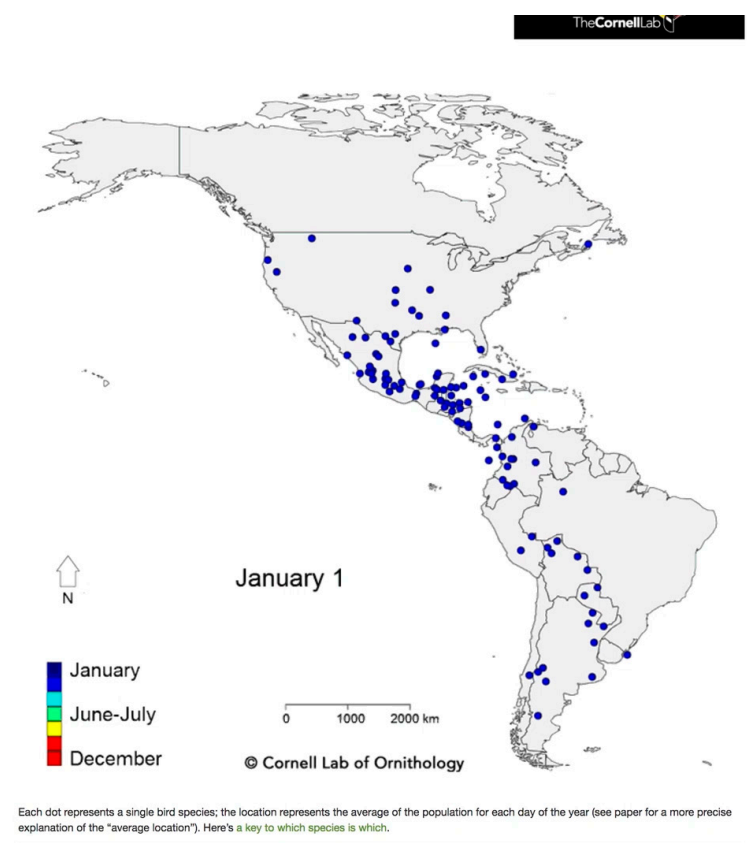

Fig. 5. A frame from an animated bird migration map, (c) Cornell Lab of Ornithology, January 2016. https://www.allaboutbirds.org/mesmerizing-migration-watch-118-bird-speciesmigrate-across-a-map-of-the-western-hemisphere/

\subsection{Highlighting and dramatizing}

The use of animation to make statements more effective and memorable dates back to the invention of animation itself. The pioneer of this use of animation for stressing a particular moment in storytelling was, again, in the entourage of Otto Neurath. It was Paul Rotha, director of one of the first documentary using animated isotype graphics, The World of Plenty (1943). There's a tone of irony and skepticism in Rotha's use of animation, as also stressed by Marie Neurath (1946) and Purdon (2016: 144.150): "First all little figures stand on the same level, which is explained as the average income. Then some lose their level, moving down - these have less than the average. Others go up. There is one figure that does not seem to stop, up and up it goes. There is a laughter of surprise" (M. Neurath, 1946) (fig. 6).

It is the same feeling one has when viewing the famous fragment of Al Gore's documentary "An inconvenient truth" (2006) where the former US vice president follows with his body and even the use of an elevator the increase of temperature due to global warming. In this case, it is not only the voiceover that adds drama to the narrated facts, but also the proxemics of the speaker. Hans Rosling knows this very well: in the already mentioned animated scatterplot, he accompanies with his physicality the moments of rise and fall of human demographics ("What a 
catastrophe!" he exclaims, while following with his body the drop of life-expectancy during the first world war).

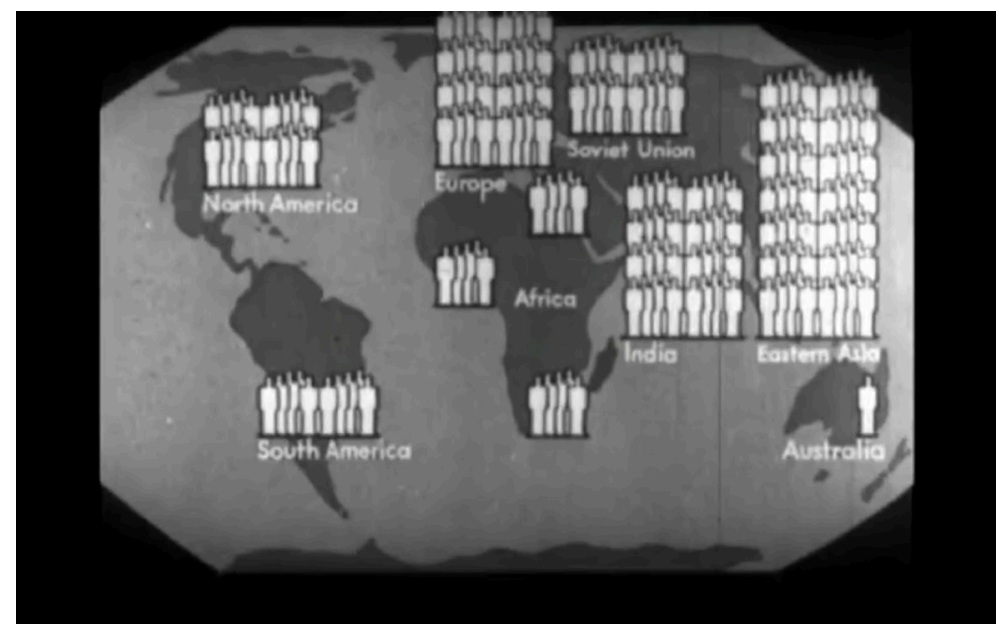

Fig. 6. A frame from The world of plenty, Paula Rotha, 1943.

Speaking about the use of isotype in animation, Marie also highlights Otto Neurath's perplexities about the use of charts in films, as the viewer had a limited amount of time to perceive the content and could not slow it down for their better understanding. Also Tufte's focus on small multiples - illustrations sequenced over time like the frames of a movie showing small sequential changes in data - is a declaration of preference for a time that is displayed in space rather than compressed in an animation (Tufte, 1990: 67-79).

\section{The role of animation in Europa Dreaming}

We will now investigate how animation was used in Europa Dreaming, a project about the return of borders in Europe.

\subsection{Transition: syntactic function}

One of the core visualizations of Europa Dreaming connects two different datasets in order to show the human transits across Europe. The first visualization (fig. 7a) shows the countries of arrival of the migrants, while the second one (fig. 7b) presents the destination countries requested by first-time asylum applications. Hypothetically relying on a more conventional visualization, the data could have been represented by two separate charts. Instead, the datasets about landings and asylum countries are connected in a single visual discourse through the use of an animated transition. 


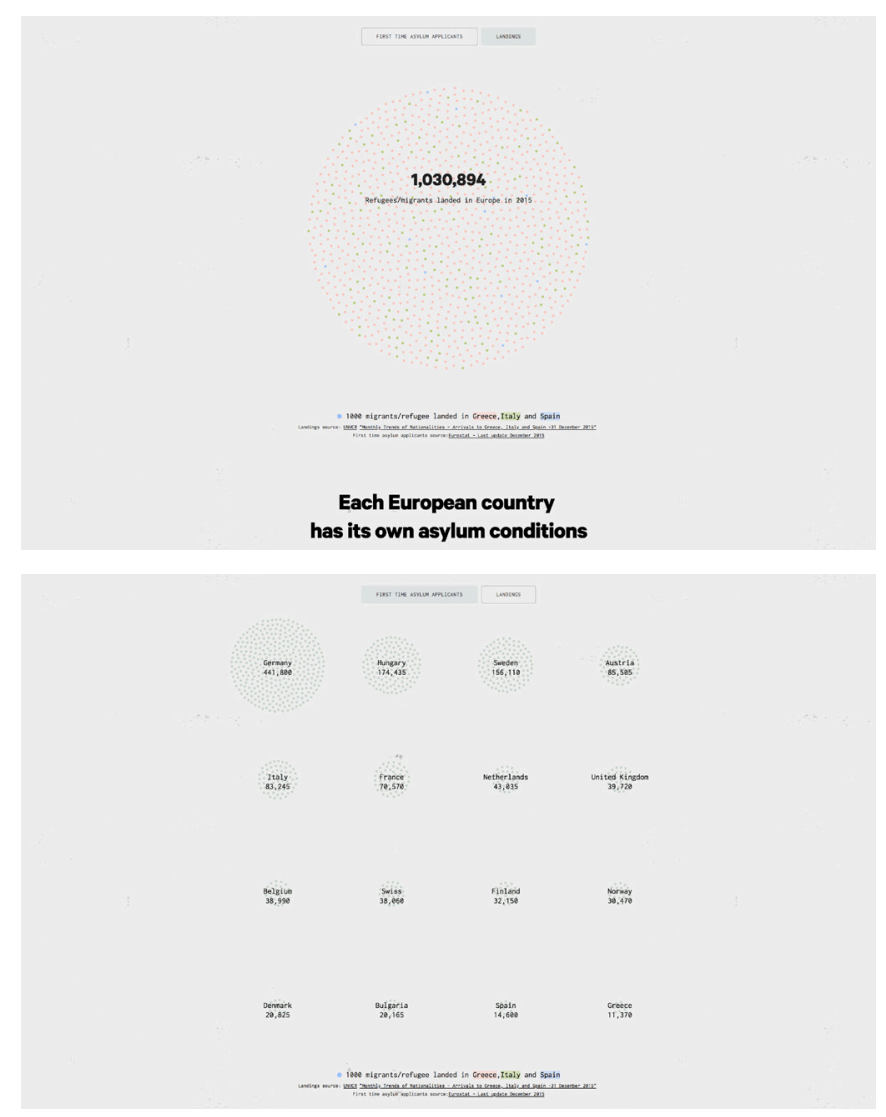

Fig. 7a. The unordered agglomerate randomly visualizing the landing countries of the migrants, Europa Dreaming, 2016. http://www.europadreaming.eu

Fig. 7b. The dots that were forming the million refugees cloud, displace on a grid, forming a series of 16 sub-clouds, Europa Dreaming, 2016.

This means that the 1030 small dots that are clustered together in a cloud depicting the 1,030,894 refugees who landed on the European coasts in 2015, suddenly begin to move randomly and relocate on a grid, forming a series 16 subclouds and generating the visualization of the main asylum application countries. The smaller bubble charts are based on the same principles as the previous one. The transition transforms two different visualizations into a single animated chart that switches between two statuses, depending on the user's choice. In other words, this animated transition connects the first visualization to the second one, creating a continuity between the moment in which migrants disembark and the future they have in mind.

Conceptually speaking, the design process shifted from the visualization of the mere numbers (landings and asylum applications) to the visualization of the people (who landed and applied). The transition from one graphic to the other reinforces the idea that it is the same persons who disembark and ask for asylum. People are represen- 
ted as a human swarm driven by a strong intentionality (the movement with which they pass from the first agglomerate to the desired countries is very direct), which is nevertheless left to roam slowly and randomly about in a limbo that is called "first country of arrival" by the Dublin regulation.

\subsection{Expressive use of animation: the human swarm}

The little dots of the first graphic (the cloud representing the countries of arrival, fig.7a) are slowly animated, evoking a living, organic agglomerate, like a nervous crowd observed from above, moving incessantly within a limited circular area. This design intervention gives rise to a visual metaphor, recalling the migrant movements constrained by the EU borders that they tried to break through in every possible way. This movement, then, does not represent a process, a passing of time, but on the contrary a situation of suspension, of waiting. The use of dots in the graphic, while remaining strictly abstract, manages to stand for people in movement, much more than the bubbles or sectors usually adopted to represent numerical quantities.

\subsection{Expressing uncertainty}

The randomness introduced in this dot-based pie-chart has also the aim of demonstrating the difficulties encountered in managing data about migration: not only is it difficult to evaluate the quantities of migrants who landed in each country (they were sometimes counted twice, or not counted at all), it is also difficult if not impossible to follow their paths across EU borders once they leave or escape from the first reception center they were assigned to.

Another infographic for which it was difficult to gather reliable enough data is the one about the times for processing asylum requests in different countries (Fig. 8).

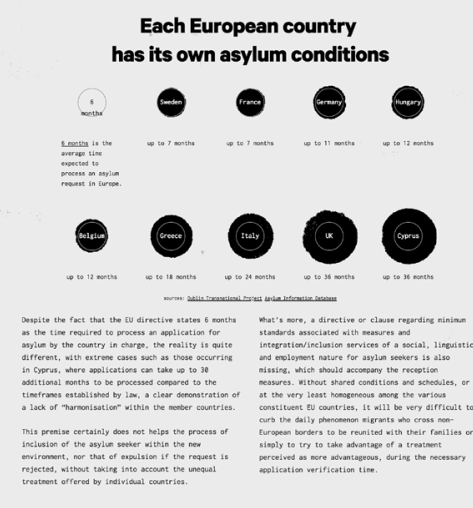

Fig. 8. Time for asylum's processing, Europa Dreaming, 2016. 
Even though the European normative on this matter establishes that the maximum timeframe to process an asylum request has to be no longer than six months, the single countries are far from respecting the law and usually take much longer. The unpredictability of the waiting time, which makes migrants float in a limbo for several months, if not years, is expressed through the movement of dripping and imprecise style of the black circles. The measure of their area should stand for the maximum waiting time for the migrants, but the animated overflowing of their border gives no certainty about it. The figurative reference to ink, bureaucracy and dribbling liquid enriches the image with further meaning which does not settle in the mere communication of numbers.

\section{Conclusions}

In the case study we analyzed above, animation has the three functions mentioned at the beginning of this paper: it draws attention; it creates meaningful transitions and, above all, gives additional connotation to numerical display. If animation is always perceived as the inclusion of a time element in a graphic, in the case analyzed the time that is depicted is a time of waiting and helplessness. The movement of swarming and the absence of clear borders in the visualization also introduces the issue of uncertainty in the data retrieved. 


\section{References}

1. Arnheim, R. (1954). Art and Visual Perception. A psychology of the creative eye. Berkeley, CA, USA: University of California Press ( $2^{\text {nd }}$ ed. 1974).

2. Cairo, A. (2012). The Functional Art: An introduction to information graphics and visualization. Berkeley, CA, USA: New Riders.

3. Healey, C.G. (2012). Attention in Visual Memory in Visualization and Computer Graphic in IEEE Transactions on Visualization and Computer Graphics. Volume: 18, Issue: 7, July 2012.

4. Finke, T., \& Manger, S. eds. (2012). Informotion: animated infographics. Berlin: Gestalten Verlag.

5. Neurath, M. (1946), Isotype in Films. Neurath (Marie), "Isotype in films" in ScannanJournal of the Portlaoghise Film Society 1, 3. Republished in: http://isotyperevisited.org/1946/06/isotype-in-films.html

6. Purdon, J. (2016). Modernist Informatics. Literature, Information and the State. Oxford: Oxford University Press.

7. Tufte, E.R. (1983). The Visual Display of Quantitative Information. Cheshire, CT: Graphics Press.

8. Tufte, E.R. (1990). Envisioning Information. Cheshire, CT: Graphic Press.

9. Virilio, P. (2009). "Stop Eject" in Native Land. Stop Eject. (Virilio P., Depardon R., Diller Scofidio + Renfro, Hansen M., Kurgan L., Rubin B.). Paris: Actes Sud. 